\title{
Assessing the Acceptability of Family Planning Services in the Rural Areas of Cross River State, Nigeria
}

\author{
Ibiang, Eno Itobo ${ }^{1} \quad$ Wofai Eno Ibiang ${ }^{2}$ \\ 1.Department of Geography CRS College of Education, Akamkpa,Cross River State, Nigeria \\ 2.The john Hopkins University School of Advanced International Studies, Washinton D.C.
}

\begin{abstract}
The purpose of this study is to examine the acceptability of family planning services in rural areas of Cross River State. The main objective of the study is to identify the relationship between availability of family planning services and the acceptability of the services by rural dwellers as well as identify the determinants of family planning service acceptability. Survey design was used in the study. The study population was all women of child bearing age. A sample size of 600 women was used for the study. The respondents used in the study were selected randomly using multiple sampling technique. A structured questionnaire designed to elicit responses on adoption of family planning services was administered to 600 people in the study area. Data collected from the respondents was analyzed using simple percentages and Analysis of Variance (ANOVA). Based on the analysis, a positive relationship was established between availability of family planning service and the acceptability of the programme by the rural dwellers. The study also identified the main predictors of family planning service acceptability.In view of the findings of the study, it was concluded that the provision of more family planning services in the rural areas would increase the level of acceptability of family planning services.
\end{abstract}

Key words: Family planning services, acceptability of family planning, rural dwellers and family sizes

DOI: $10.7176 /$ RHSS/10-12-02

Publication date:June 30th 2020

\section{Introduction}

The impact of rapid population growth on available resources has been a source of concern in recent time. The population of many countries has a shorter doubling time, implying that the population growth is so rapid that it is not keeping pace with the available resources. Rapid population growth is often traced to the practice of having large family sizes among other factors, (AttahGutmacher Institute 1998). Large family sizes are more prevalence among rural dwellers who seldom practice birth control. Most families in rural areas have exceeded the National population policy prescribed family size of four children per family. The existence of large family sizes implies that family planning services are poorly utilized in the rural areas. In line with this assertion, the Centre for Disease Control and Prevention identified that teens births rates are higher in rural areas than urban centers. Kenfinner (2013) argued that births rates in rural areas of Nigeria are 43 per 1000 females as against 33 births per 1000 females in urban centers. This statistics shows that for population control to be effective, the family unit must be the core of population issues and planning, be it fertility or mortality rates (Odibo, 2004).

Family planning is a component of Nigerian national population policy designed to regulate births at family level and consequently to control rapid population growth. The implementation of family planning programme unfortunately varies among nations. Some countries perceived rapid population growth as an asset and therefore do not emphasis birth control measures. Others view rapid population growth as a threat to the welfare of citizens and therefore agitate for the introduction of family planning services. Controversy therefore abounds in the introduction of family planning services among nations and even among ethnic and religious groups, such that the acceptability of the programme varies within regions.

Nigeria with a multiplicity of ethnic and religious groups is bound to view the introduction of family planning programme in different ways. The perception towards family planning programme by the different socio-cultural groups determined the level of acceptability of family planning services among people. It is from this background that the need to examine the acceptability of family planning services in the rural areas of Cross River State becomes imperative.

Cross River State is located between Latitude $6^{0} 21^{1}$ and $6^{0} 43^{1}$ and Longitude $3^{0} 8^{1}$ and $4^{0} 17^{1}$. It is bounded in the south by the Atlantic ocean, north by Benue state. In the west by Abia state and Ebonyi and in the East by Republic of Cameroun. It has a population of 2.3 million and population growth rate of $3.6 \%$ (NPC, 2006). About $48 \%$ of the population are females and $52 \%$ are males (NPC, 2006). The population has a tendency of doubling itself within 25 years. The state has abundant natural resources which are gradually being deleted as a result of rapid population growth. This implies that efforts towards controlling the population growth are imperative.

Cross River State is predominantly agrarian and rural in nature. The rural areas lack modern infrastructure including health care facilities. More often the rural dwellers depend more on the traditional health care system for their medical needs.

The state being an agrarian society depends majorly on family labor for farm work and as such value large 
family sizes. Some citizens of the state are still engaged in family life practices such as male child preference, family child labor that result in rearing of large family sizes. Children are therefore seen as a blessing and a source of wealth. This perception of children has affected how people accept family planning programme in the area. Many people in the study area have not accepted family planning or birth control. Others have not adopted the programme as a result of the near absence of family planning services in the area. These situations tend to limit the adoption of family planning services in rural areas. It is from this background that an assessment of the acceptability of family planning programme in rural areas becomes necessary.

It follows that issues and policies which focus on population control; be it birth control or family planning programme must consider the family unit. It is from this perspective that the acceptability of family planning service among the rural dwellers is being assessed to ascertain the level of acceptance in recent time.

The question then is what is family planning? It simply means the planning of family size in a manner compatible with the physical and socio-economic resources of parents and conducive to the health and welfare of members of the family (Gupta, 2005). This is achieved by adopting birth control strategies made available through family planning programmes. The adoption of family planning services often assist individuals or couples to avoid unwanted births, bring about wanted birth; regulate the intervals between pregnancies to desired time at which birth occur in relation to ages of parents and determine the number of children in a family (Park, 2007).

The rationale for the adoption of family planning are economic, demographic and health (society for Family Health, 2006). Family planning programme is pursued by providing family health care related services including modern methods such as contraceptive pills, intrauterine devices, injections, male and female condoms, diaphragm, male sterilization and other traditional methods like breast feeding, rhythm and withdrawal methods. These services are provided in the health care centres and hospitals.

The adoption of these services by individuals and couples tend to be low in Nigeria. The Federal Ministry of Health in 2002 stated that among adolescents and young persons, contraceptive use is very low, resulting in high prevalence of undesirable pregnancies, unsafe abortion and mortality. Ramaro, Lacusta Castella, Pangolibrary and Jones (2003) in accepting the above assertion stated that contraceptive prevalence is still very low in Nigeria. FMOH, (2010) stated the contraceptive prevalence rates over the years as follows; $8.2 \%, 12 \%, 14.6 \%$ for 2004 , 2007 and 2008, respectively. These rates are very low in the face of high rate of sexual activity and widespread knowledge of contraceptive methods argued Monjok, Andrew, John and Essien (2010). The low prevalence is according to Ekong (2016) attributed to poor accessibility to family planning services by the rural dwellers. Apart from this factor, Aslan, Ozeebe, Billr, Vaizoglu and Sahazi (2006) identified other factors influencing acceptability of family planning services to include; educational status, income, availability of services, awareness, presence of a health insurance scheme among others. It is from these factors, some of the variables used in this study are derived.

The purpose of this study is to examine the acceptability of family planning programme among rural dwellers in Cross River State, Nigeria. To achieve this purpose, the following objectives were pursued;

1) To identify the relationship between availability of family planning services and its acceptance by rural dwellers in the study area.

2) To identify the factors influencing acceptability of family planning programme.

The rationale of the study is based on the fact that the world-over is currently placing emphasis on family size reduction as a strategy towards controlling rapid population growth. It has therefore become imperative for rural dwellers to key into the family planning programme. An assessment of acceptability of family planning would expose the problems and challenges facing family planning acceptability. This would guide appropriate policy formulation. This study would also stimulate comparative studies in family planning service provision, utilization and acceptability.

In pursuance of the objectives, the following research questions are raised;

1) What is the relationship between the acceptability of family planning programme and the availability of family planning services among the rural dwellers?

2) Is there any relationship between provision of family planning services and the acceptability of family planning services?

The formulated research questions were translated into research hypotheses stated in null forms as follows; 1) Inadequate provision of family planning services do not affect the acceptability of the family planning programme by rural dwellers.

2) The personal attributes of the rural dweller do not affect the acceptability of family planning services

Survey design was adopted in the study. This is because of the nature of data. Primary and secondary data on family planning acceptors was collected from the Ministry of Health and hospitals in the study area. The primary data was generated from a structured questionnaire designed to elicit responses on acceptability of family planning programme. The secondary data focused on the availability and patronage of family planning services in the study.

All women of child-bearing age constituted the study population. A sample size of six hundred women was 
used for the study. The selection of the 600 women was done using stratified random sampling technique. The randomly selected women constituted the respondents who responded to the questionnaire designed to elicit responses on socio-economic characteristics of respondents and acceptability of family planning services.

The collected data was computed and analyzed using simple percentage to facilitate understanding and comparism. This analysis may not show complex relationship between the variables. In view of this, a more rigorous statistical technique such as a two way ANOVA was used in testing the formulated hypotheses. While multiple-regression analysis was used in identifying the contribution of each variable to the variation in the acceptability of family planning services in the study area.

In testing the hypothesis, if the calculated value is higher than the critical value, the null hypothesis $\left(\mathrm{H}_{0}\right)$ will be rejected at 0.5 level of significance while where the calculated value is lower than the critical value, the alternate hypothesis will be accepted.

\section{Result}

The result of the study is presented hypothesis by hypothesis as follows:-

Hypothesis I, which stated that availability of family planning services do not affect the acceptability of family planning programme by rural dwellers was tested using a two-way analysis of variance (ANOVA). The result was presented in Table 1.

TABLE 1: Two-Way ANOVA on Availability and Acceptability of Family Planning Services in Rural Areas of the Study Area

\begin{tabular}{|l|c|c|c|c|c|}
\hline $\begin{array}{c}\text { Source of } \\
\text { variation }\end{array}$ & $\begin{array}{c}\text { Sum of squares } \\
(\mathrm{SS})\end{array}$ & $\begin{array}{c}\text { Degree of } \\
\text { Freedom (df) }\end{array}$ & $\begin{array}{c}\text { Mean square } \\
(\mathrm{MS})\end{array}$ & f & Sig. of f \\
\hline Between groups & 1485.88 & 2 & 136.08 & & \multirow{2}{*}{7.15} \\
\hline Within groups & 7477.12 & 26 & 19.271 & 000 \\
\hline
\end{tabular}

Table 1 showed the calculated F-value as 7.01 and the critical value at 0.05 level of significance as 3.40. This implies that the calculated $\mathrm{F}$ value is greater than the table value. It therefore follows that the null hypothesis which states that the availability of family planning services does not affect the acceptability of family planning is rejected while the alternate hypothesis which states that the availability of family planning services affect the acceptability of family planning services is accepted.

This result is supported by table 2 which shows the availability of family planning services and the number of people utilizing the services in the study area.

Table 2: Availability and utilization of family planning services

\begin{tabular}{|l|l|c|c|}
\hline s/n & Availability of family planning services & $\begin{array}{l}\text { Utilization of family planning } \\
\text { services }\end{array}$ & $\begin{array}{l}\text { Percentage of utilization } \\
\text { of } \\
\text { family } \\
\text { services }\end{array}$ \\
\hline 1 & Contraceptive pills & 32 & 5.3 \\
2 & Intrauterine devices & 6 & 1.0 \\
3 & Injections & 16 & 2.7 \\
4 & Condoms & 118 & 19.8 \\
5 & Diaphragm & 3 & 0.5 \\
6 & Sterilization & 2 & 0.33 \\
7 & Rhythm method & 13 & 2.4 \\
8 & Induced abortion & 27 & 4.6 \\
9 & Traditional methods & 41 & 6.0 \\
10 & None utilization of any service & 342 & 57.0 \\
\hline \multicolumn{2}{|r|}{ Total } & 600 & 100 \\
\hline
\end{tabular}

Table 2 shows that $57 \%$ of rural dwellers do not adopted any family planning services. In other words, only $43 \%$ of women of child bearing age have adopted one form of family planning services or the other. Among the available services, the most patronized is condoms, which has $19.8 \%$ acceptability followed by contraceptive pills with 5.3\% acceptability. The least patronized family planning services are diaphragm, sterilization and intrauterine devices which has $0.5 \%, 0.33 \%$ and $1.0 \%$ acceptability respectively. The low acceptability may be due to the unavailability of such services in the health centers located in the rural areas or the sophisticated nature of the services which require specialists to handle, as well as lack of awareness of the services by the rural dwellers.

To explain the observed variation in the utilization of family planning services, a multiple regression analysis, stepwise model was applied to the equation. The result is as presented in table 3 . The result shows the F-ratio as 301.07 , the correlation coefficient $(\mathrm{R})$ as 0.936 and the coefficient of determination $\left(\mathrm{R}^{2}\right)$ as 0.68 . This result is interpreted to mean that the variables used in the study explained $68 \%$ of the variation while the error is $32 \%$. 
Table 3: Multiple-Regression Analysis of variables affecting the acceptability of Family Planning Services

$\begin{array}{lr}\text { Multiple R } & 0.936 \\ \mathrm{R}^{2} & 0.676 \\ \text { Standard error } & 0.22972\end{array}$

\begin{tabular}{|c|c|c|c|c|c|}
\hline Source of Variation & $\mathrm{SS}$ & $\mathrm{df}$ & Ms & $\mathrm{t}$ & Sig. \\
\hline Regression & 324.96 & 16 & 20.31 & 301.07 & .000 \\
\hline Residual & 45.80 & 1090 & 0.67 & & \\
\hline TOTAL & 370.76 & 1106 & & & \\
\hline
\end{tabular}

Predictors: Constant (acceptance of service), availability of services, socio-economic status, educational status, socio-cultural affiliation, perception of services

Table 3(b): Parameters Estimates

\begin{tabular}{|lccccc|}
\hline \multicolumn{1}{|c}{ Variables } & B & SE.B & Beta & T & SGN \\
\hline Constant & -.226 & -.104 & & -2.181 & .029 \\
Availability of services & .000 & .001 & .004 & .252 & .3010 \\
Income of persons & .969 & .680 & .068 & -3.452 & .1404 \\
Education status & 1.272 & .620 & .097 & -1.146 & .1923 \\
Quality of services & -.405 & .414 & -064 & .018 & .056 \\
Access to information & -1.309 & 1.143 & -.054 & 2.099 & .0118 \\
Religious belief & .595 & .414 & .414 & -.325 & .0309 \\
Tradition \& customs & .405 & .643 & -.209 & .026 & .1404 \\
Perception towards family planning & -.585 & .258 & -.725 & .939 & .082 \\
\hline
\end{tabular}

Dependent variable: Family Planning Services

* Significant relationship culled from computer print out

Table 3(b) identified the variables that contributed to variation in the acceptability of family planning services. The identified variables were availability of family planning services, which accounted for $30.10 \%$ of variation. This implies that the availability of family planning services is very fundamental in promoting the level of acceptability of the services. The second most important variable predicting the acceptability of family planning is the educational status of the people, followed by the socio-economic status which accounted for $19.23 \%$ and $14.04 \%$, respectively.

The contribution of other variables in predicting the acceptability of family planning services are as follows; cultural practices, $14.04 \%$; religious belief, $3.09 \%$ individual perception towards family planning $8.20 \%$.

\section{Discussion of Result}

The result established a positive relationship between availability of family planning services and acceptability of family planning services among the rural dwellers in the study area. This implies that the low level of the acceptability of the family planning services is as a result of inadequate provision of the family planning services. The family planning services are only provided in health centres and hospitals which are not very accessible to many people. The high acceptability of some family planning services such as the use of condoms and contraceptive pills is because the services can be easily obtained from the health centers and medicine stores which are found all over the study area. These services do not require a specialists to administer and are affordable.

The study also revealed the variables influencing the acceptability of family planning services to include; availability of services, socio-economic and educational status, cultural practices, religious beliefs and perception towards family planning. These factors tend to predict the acceptability of family planning services. It therefore implies that, a positive improvement in any of these predictors would improve the acceptability level of family planning services in the study area.

The impact of these variables in the adoption of family planning is justified by the fact that the rural population is dominated by low income earners, high illiterates and un-informed population. The rural dwellers are also tied to traditional and cultural beliefs which are opposed to orthodox family planning methods. Such a population may not easily accept new ideas such as the introduction of birth control measures aimed at reducing birth rates. Strategies designed to change the present characteristics of the rural population would enhance the acceptability of family planning services in the study area.

\section{Conclusion}

Rapid population growth in rural areas of Cross River State can be checked if only people are prepared to adopt family planning or birth control measures as encapsulated in the family planning programme. It is worrisome that despite the increasing provision of family planning services and campaigns, the acceptability of family planning 
services by rural dwellers remains still very low. About $57 \%$ of rural dwellers in Cross River State are yet to adopt family planning or birth control measures aimed at reducing family sizes. The inadequate provision of family planning services in the rural areas tends to influence the acceptability of family planning services. Infact this study established that a positive relationship exists between availability of family planning services and the acceptability of family planning services among the rural dwellers. It is also established that family planning services which are more accessible are highly patronized than those that are not accessible. No wonder, services such as condoms, contraceptive pills provided in hospitals, health centers and patent medicine stores are receiving more patronage than those that are hospital base.

It is however observed that the acceptability of family planning services in the study area is predicted by the availability of the services, the socio-economic status, educational status, cultural and religious beliefs of the people and the individual perception towards family planning programme. These factors accounted for about $68 \%$ of the variation in the acceptability of services provided through the family planning programme.

The positive correlation between availability of family planning services and its acceptability Implies that an improvement in the variables affecting the acceptability of family planning service would lead to improvement in the acceptability in family planning services in the study area. Such an improvement in the level of family planning acceptability would result in the reduction of family sizes and eventually slow down the population growth. Such development would promote sustainable development and improve quality of life of the people.

\section{Recommendation}

In view of the findings of this study, the following recommendations are proffered;

1) Deliberate attempts should be made towards adequate provision of family planning services in the rural areas. This should not be left to government alone, individuals and non-governmental organizations should assist in providing these services.

2) Programmes which would increase the literacy level and awareness of the rural dwellers should be introduce with a view to increasing the literacy level of people.Public enlightenment and adult education programmes on population issues could boost the acceptability level of family planning services.

3) Introduction of poverty eradication programmes could improve the income level of the rural people, if there is a boost in the income level of the rural people, the family planning services would be more accessible and affordable. More rural empowerment programmes is advocated.

4) National survey on the adoption of family planning services as a way of controlling birth rates should be conducted to enhance proper policy formulation.

\section{References}

Aslan, D. Ozeebe, H, Bilir, N; Vaizoglu, S. and Sahazi, N. (2006) What are the predictors of Health Service Utilization by Woman in a City Centr located in Eastern Turkey: A Cross Sectional Study, Turkey Journal of Medical Science. 36:37-43.

AttahGuttmacher Institute (1998), Sharing responsibility. Women Society and abortion Worldwide, Washington DC: AGL.

Centre for Disease Control and Prevention (CDC) (2009), Blood disorders' [Online] Available Http/www.gov/ ncbdd/default.htm.( September $\left.12^{\text {th }}, 2014\right)$.

Federal Ministry of Health (2010) Nigeria Millennium Development Report. Abuja, Nigeria.

Gupta, M. C. and Maliajan, B. K. (2005) Textbook of Preventive and Social Medicine (3 ${ }^{\text {rd }}$ ed). New Delhi; Jaypes Brothers.

Ituen, U. J. \&Uzoma, E. I. (2018), Spatial Distribution of Family Planning Services and Acceptors in AkwaIbom State, Nigeria. Geography and National Development. A Festschrift in honour of Prof. Philip A. Akpan and Prof. Idorenyin BobInyang. A Publication of the Department Geography and Natural Resource Management, University of Uyo, Uyo - Nigeria.

Johnson, D \&Ekong, I. (2016) Knowledge, Attitude and Practice of Family Planning among Women in a Rural Community in Southern Nigeria. British Journal of Medicine \& Medical Research 12(2): 1-8.

Monjok, E.; Andrew, S; John, E. E. and Essien, J. E. (2010) Contraceptive Practices in Nigeria. Literature Review and Recommendation for Future Policy Decisions. Open Access Journal of Contraceptive, 1: 9 - 22.

Odibo, A. A. (2004) Family Life and Sex Eduction, Warri: COEWA Publishers (EP).

Park, K. (2007) Preventive and Social Medicine (19 ${ }^{\text {th }}$ edition) Jahalpur: BanrsidasBhanal Publishers.

Ramaro, S; Lacusta, M, Castella, M; Pangolibrary, B. and Jones, H (2003). The link between quality care and contraceptive use. International Family Planning Perceptive, 39(3): 71-83.

Society for Family Health (2006) Strategic Retreat on Behaviour Change and Communication for Family Planning, Ibadan: Heinemann.

World Bank (2007) Reproductive Health at a glance. Washington D. C. World Bank. 


\section{About the Authors}

Eno Itobo Ibiang is an academic and the current dean of school of arts and social sciences, CRS college of education, Akamkpa, Nigeria. He is a development studies expert and has M.sc in population studies and a Ph.D in geography in geography specialized in rural planning and development.

Wofai Eno Ibiang is an international development professional and master of international public policy (MIPP) Graduate of the John Hopkins University, Washinton DC, USA. 